\title{
Extra-Corporeal Shock Wave Lithotriposy ( ESWL ) for Lower Ureteral Stone
}

\author{
Othman Jasim Mohammed Alzaidy (FIBM (URO) $)^{1}$ and Reyad Ahmed Farhood \\ $(\text { FIBM }(\mathrm{URO}))^{2}$
}

\begin{abstract}
Background: The optimal treatment of ureteral stones, particularly the lower ureteral stone, still controversial[5,13,15,18].

Objective: To assess the success rate of ESWL and tamsulosin in lower ureteral stone. Also to identify the parameters that affects the success rate of ESWL in the lower ureteral stone.

Patients and Methods: Prospective study has been done on thirty-six patients sequentially selected from referred cases to the ESWL department in Sulaimania Teaching Hospital in the period from June, 2010 to January, 2011). All had radioopaque lower ureteric stone (from the lower border of sacroiliac joint to uretero-vesical junction). Stones ranging from (5.8 to $14 \mathrm{~mm}$ ), twenty in the left side and sixteen in the right side, age ranging from (10 to 78 years), and only four of them had double J-stent (within 1 week before ESWL). Weekly follow up of all patients were done by U/S and twice-weekly by KUB for 6 weeks.

Results: Twenty four cases $(66.7 \%)$ were free of stone, five cases $(13.9 \%)$ had residual stone and seven cases $(19.4 \%)$ failed to respond, the most important two parameters that affect the result are the size of stone and number of sessions.

Conclusion: ESWL is safe and useful, and it is considered to be the first favorable line of intervention for lower ureteric stones after failure of watchful waiting and medical expulsion therapy especially those without complications like obstruction.

Keywords: Lower ureteric stone, extracorporeal shock wave lithotripsy

Corresponding Author: othmanalzaidy@ gmail.com

Received: $20^{\text {th }}$ September 2020

Accepted: $24^{\text {th }}$ September 2020

DOI:https://doi.org/10.26505/DJM.19025670920

${ }^{1,2}$ Baquba Teaching Hospital - Diyala- Iraq

\section{Introduction}

Urinary calculi are the third most common affliction of the urinary tract, exceeded only by urinary tract infections and pathologic conditions of the prostate[2]. Most calculi arise in the kidney when urine becomes supersaturated with a salt that is capable of forming solid crystals[3]. The ureter anatomically has three parts: the upper ureter,

from the ureteropelvic junction to the superior margin of the sacrum; the mid part, from the upper to the lower edge of the sacroiliac joint; and the lower part, from the lower edge of the sacrum to the vesicoureteral junction $[4,5]$. Ureteric stones mostly become lodged at three main positions where the diameter of the ureter
\end{abstract}


become narrower: the ureteropelvic junction, the iliac vessels, and the vesicoureteral junction. Most of the time small ureteral stone will pass spontaneously within days or few weeks. Delay in the relieve of obstruction might cause irreversible kidney damage[5].

Ureteric calculi bigger than $5 \mathrm{~mm}$ are less likely to pass spontaneously while the aim of the interventional management of patients complaining of ureteric stones is to have stones free situation with the least complications[7]. The lines of management are passage of double $\mathrm{J}$ stent placement, extracorporeal shockwave lithotripsy, ureterorenoscopy with basket extraction or intracorporeal lithotripsy and open surgery. Open surgical procedure is seldom nowaday.

The optimal treatment for distal ureteral calculi remains controversial, the most important point of controversy is whether to use shock wave or ureterorenoscopy[5,13,15$18]$.

\section{Patients and Methods}

A prospective study has been done on thirty-six patients, they were sequentially selected from referred cases to the ESWL department in Sulaimania Teaching Hospital in the period from June, 2010 to January, 2011.

The sample inclusion criteria were solitary lower ureteric stone (any stone from the lower border of the sacroiliac joint to the UVJ ), both genders (30 males and 6 females) . The exclusion criteria were multiple lower ureteric stones, previous intervention, radiolucent stones, females below 50 years of age (as ESWL is relatively contraindicated in lower ureteric stones), and single kidney. The stones were ranging from (5.8 to $14 \mathrm{~mm})$, all were radio-opaque, 20 in the left side and 16 in the right side, age ranging from (10 to 78 years), only one of them need analgesia( 10 years )and only four of them had JJ stent within one week before ESWL.

A complete medical history was taken from all patients, clinical examination, a plain abdominal X-ray (KUB), and ultrasonography of the abdomen and pelvis were done.

The U/S was performed by a specialist, and the degrees of the hydronephrosis identified as mild, moderate and severe hydronephrosis. Regarding ESWL: a number of ESWL session were ranging from (1-5 )sessions, number of shock waves (5000sw/second), energy level (7.5-8 Kv) and the consumed time for any session were (30- 45 minutes ), all of them received ESWL in the prone position.

Weekly follow up of all patients were done by U/S and twice-weekly by KUB for 6 weeks and all of them received tamsulosin (a highly selective $\alpha$-adrenoceptor blocker) post ESWL in a dose of $0.4 \mathrm{mg}$ for adult and 0.2 mg for only 10 years old child until they became stone-free within 6 weeks, if not we stopped, and sent them for other options.

ESWL machine was LITHOSTAR Multiline (SIEMENS) (Germany), this is the electromagnetic type and functioning under fluoroscopic imaging. Successful ESWL was considered for patient with no stone by U/S and KUB. Residual stone was defined in the cases of passage of the stones and reduction in the size of original stone by U/S and KUB. Failure of ESWL was regarded in patient with the same size stone after ESWL. 


\section{Statistical analysis}

The results were evaluated statistically using the statistical package for the social sciences (SPPS) version 15. All the data were expressed as mean \pm SD and SE. Comparison between groups were made by using the Turkey test. Independent t-test was used to compare the results. Statistical significant results were considered when $\mathrm{P}$-value was < 0.05 .

\section{Results}

Thirty-six cases with solitary lower ureteric stone enrolled to this study, from which twenty four cases $(66.7 \%)$ free of stone, five cases $(13.9 \%)$ had residual stone and seveen cases (19.4\%) failed to respond (Figure 1). Stone-free rate after $1^{\text {st }}$ week was 6 cases $(16.7 \%)$, after 2 weeks 4 cases $(11.1 \%)$, after 4 weeks 8 cases $(22.2 \%)$ and after 6 weeks 6 cases $(16.7 \%)$ Table(1).

Table (1): Percentage of stone free rate according to time after ESWL

\begin{tabular}{||l||c||c||}
\hline & Frequency & Percentage \\
\hline Stone fr ee after 1 wk & 6 & 16.7 \\
\hline Stone fr ee after 2 wks & 4 & 11.1 \\
\hline Stone fr ee after 4 weeks & 8 & 22.2 \\
\hline Stone fr ee after 6 weeks & 6 & 16.7 \\
\hline
\end{tabular}

Gender: 30 cases $(83.3 \%)$ were males and 6 cases $(16.7 \%)$ were females Those with stone-free: 3 cases $(12.5 \%)$ of them had no hydronephrosis, 16 cases $(66.7 \%)$ had mild hydronephrosis, 4 cases $(16.7 \%)$ had moderate hydronephrosis and one case (4.2\%) had severe hydronephrosis Table (2).

Table (2): Success rate in relation to gender, stone size, degree of hydronephrosis and jj stenting

\begin{tabular}{|l||c||c||}
\hline \multicolumn{1}{|c|}{ Variables } & Success N (\%) & P-value \\
\hline Stone size & & \\
\hline 10mm or les & $18(75.0)$ & 0.022 \\
\hline More than 10mm & $6(25.0)$ & \\
\hline Degree of hydronephrosis & & \\
\hline No & $3(12.5)$ & \\
\hline Mild & $16(66.7)$ & 0.422 \\
\hline Moderate & $4(16.7)$ & \\
\hline Sever & $1(4.2)$ & \\
\hline Double J stenting & & \\
\hline Yes & $3(12.5)$ & 0.521 \\
\hline No & $21(87.5)$ & \\
\hline \hline
\end{tabular}

Mean age of all cases was 40.53 years (age between 10- 78 years) Table(3). 
Table (3): Mean of age

\begin{tabular}{||c||c||c|c||c||}
\hline & Minimum & Maximum & Mean & Std. Deviation \\
\hline Age(years) & 10 & 78 & 40.53 & 15.114 \\
\hline
\end{tabular}

Mean size of stone in those who were free of size of stone in those who failed to respond stone $(9.41 \mathrm{~mm})$, mean size of stone in those (11.43mm) Table (4).

who had residual stone $(11.4 \mathrm{~mm})$ and mean

Table (4): $\mathrm{P}$ value of age, stone size and number of sessions in relation to success rate

\begin{tabular}{|c|c|c|c|c|}
\hline \multirow[b]{2}{*}{ Var iables } & \multicolumn{3}{|c|}{$\begin{array}{c}\text { Success rate } \\
(\text { Mean } \pm \text { Std. Deviat ion) }\end{array}$} & \multirow[b]{2}{*}{$P$ value } \\
\hline & Failure(19.4\%) & Success $(66.7 \%$ & Residual stone(13.9\%) & \\
\hline Stone size & $11.43 \pm 1.90$ & $9.41 \pm 1.83$ & $11.40 \pm 1.34$ & 0.013 \\
\hline Number of session & $3.60 \pm 0.57$ & $2.21 \pm 0.88$ & $3.00 \pm 0.89$ & 0.003 \\
\hline
\end{tabular}

Regarding the degree of hydronephrosis:

3 cases $(8.3 \%)$ had no hydronephrosis, 22 cases $(61.1 \%)$ had mild hydronephrosis, 10 cases $(27.8 \%)$ had moderate hydronephrosis and one case $(2.8 \%)$ had severe hydronephrosis.

Stone size: In patients who were stone- free 18 cases $(75 \%)$ had stone equal or less than $10 \mathrm{~mm}$ and 6 cases $(25 \%)$ had stone more than $10 \mathrm{~mm}$ (Table 2 ), 3 cases( $12.5 \%$ ) with jj stent were stone free (Table 2), one of them passed the stone before JJ stent removal and the other 2 cases passed the stones after JJ removal.

About the number of sessions: Those who were stone- free, a mean number of sessions were (2.21), those who had residual stone a mean number of sessions were (3) and those who failed to respond had a mean number of sessions of (3.6 ) Table (4).

Statistical analysis showing significant correlation between:

a-Success rate and stone size (pvalue $=0.013$ which was significant Table (4).

$\mathrm{b}$-Success rate and number of $\operatorname{session}(\mathrm{p}$ value $=0.00)$, which was significant Table (4).
Statistical analysis showing insignificant correlation between:

a-Success rate and degree of hydronephrosis $(p-v a l u e=0.422)$, which was not significant Table (2).

b-Success rate and JJ stenting ( $p$-value $=0.521)$, which was not significant Table (2).

\section{Discussion}

Regarding ureteric stones, the treatment that receives higher recommendation may depend on many factors like stone size, composition, patient occupation, distance from the hospital, patient opinion, the experience of urologist, and availability of equipment $[4,8]$.

If we compare our study to a nearly similar study that which was done in the Sulaimania Teaching Hospital on ESWL in the treatment of ureteric stones in the year 2006, 24 patient included with lower ureteric stone and followed them for 6 months in which $(58.3 \%)$ were free of stone, $(29.2 \%)$ had residual stone and $(12.5 \%)$ were failed after ESWL, and the factor that affects the rate of stone disintegration were the size of the stone, number of the sessions (high number 
of the sessions were significant) and number of shock waves[3,9].

In our study $(66.7 \%)$ were free of stone, $(13.9 \%)$ had residual stone and $(19.4 \%)$ were failed after ESWL and the factor that affects the rate of stone disintegration stone size and number of sessions[7,11].

From this: success rate of our study was higher than the result study in spite of longer follow up that was done in that study and this may be explained by the effect of tamsulosin that was used in our study (tamsulosin may assist stone passage and reduce frequency of the ureteric colic.) $[9,12]$.

Another different point is low number of sessions were significant in our study. Another comparison with the result of study which was done in Iraq in the year 2002, it had studied the effect of ESWL on distal ureteric stone, 70 patients included, $(68.5 \%)$ of them were stone free and the factor that affects the rate of stone disintegration was only the size of the stone[11].

Also, it was showing nearly the same result, but the only difference is that we found 2 possible factors that affect the rate of stone fragmentation.

Another study was done in United Arab Emirates, in which forty-nine patients had lower ureteric stones. The overall clearance rate for the lower ureteric stones was $69.3 \%$ with 3 months follow up and stone size only affects fragmentation rate, also this is near to our result with only difference in another factor which was found in our study (number of sessions) [16]. From our result we concluded that there are two important parameters that can be taken into consideration when dealing with a patient having a lower ureteric stone and need to be treated by ESWL. These parameters are:

- Size of the stone: stone equals or less than $10 \mathrm{~mm}$ is significant ( $\mathrm{p}$-value $=0.013$ ), which was significant. There is a significant relationship between the size of the stone and its response to ESWL (the larger the stone, the less response to ESWL).

- Number of sessions of ESWL: low number of sessions ( $p$-value $=0.003$ ) is significant. If the stone is not fragmented in early sessions, it is less likely to be fragmented later. Failure of initial ESWL is associated with a low success rate for subsequent ESWL. Therefore, if ESWL has no effect after 1 or 2 treatments, the changes will tactics.

\section{Conclusions}

Extracorporeal Shock Wave Lithotripsy is safe, useful, and it is considered to be the first favorable line of intervention for solitary lower ureteric stone after the failure of watchful waiting and medical expulsion therapy. An effective and reliable outcome can be expected from ESWL treatment when we take into consideration some important points like the stone size and number of sessions of ESWL.

\section{Recommendations}

Extracorporeal shock wave lithotripsy is recommended for the treatment of lower ureteral stones after the failure of watchful waiting and medical expulsive therapy as a less invasive procedure before any endoscopic or surgical intervention.

Also, further study is recommended to compare extracorporeal shock wave lithotripsy efficacy in relation to CT scan Hounsfield units of the stone. 


\section{References}

[1]Lester PW, Hoo YW, and Donald PG: Treatment options in Struvite stones. Urol clin N AM 1997; 24:149-162.

[2]Smith's General Urology ,Emil A. Tanagho, Jack W. McAninch ,(17th) edition(2008),P-246,267.

[3]Sandy C : Renal calculi. e Medicine Journal 2001; 7:1-17.

[4]Oxford specialist handbooks in surgeryurological surgery-, $1^{\text {st }} \quad$ edition,(2008),p444,454 .

[5]Campbell-Walsh urology: Kavoussi, novick, partin, peters, International edition, $9^{\text {th }}$ edition (2007), p-1450,1451,1455.

[6]James E. Lingeman, Md Brian R. Matlaga, Md, Mph Andrew P. Evan, Phd: Campbell-Walsh Urology, $9^{\text {th }}$ ed.2007.

[7]Merck manuals > Symptoms and Diagnosis of Kidney and Urinary Tract Disorders Last full review/revision March 2007 by Ralph E. Cutler.

[8]Segura JW et al.(1997)Ureteral stones guidelines panel summary report on the management of ureteral calculi.J Urol 158:1915-21.

[9]Miller OF et al. (1999) Time to stone passage for observed ureteral calculi.J Urol 162:688-91.

[10]Holm-Nielsen A, Jorgensen T, Mogensen P, Fogh J (1981) The prognostic value of probe renography in ureteric stone obstruction . Br J Urol 53:504-7.

[11]Oxford handbook of urology, (2006) P388.

[12]Segura JW, Preminger GM, Assimos DG, Dretler SP, Kahn RI, Lingeman JE, et al.: Ureteral Stones Clinical Guidelines Panel summary report on the management of ureteral calculi. The American Urological Association. J Urol. 1997; 158: 1915-21. [13]Assimos DG, Boyce WH, Harrison LH, McCullough DL, Kroovand RL, Sweat KR: The role of open stone surgery since extracorporeal shock wave lithotripsy. J Urol. 1989; 142: 263-7.

[14] Assimos DG, Boyce WH, Harrisson LH, McCullough DL, Kroovand LR, Sweat KR. The role of open surgery since extracorporeal shock wave lithotripsy. J Urol 1989;142:2637.

[15]Preminger G M. Technique versus technology: What is the most appropriate method for the removal of ureteral calculi [editorial]? J Urol1994; 152:66-7.

[16]Hofbauer J, Tuerk C, Hobarth K, Hasun R, Marberger M. ESWL in situ or ureteroscopy for ureteric stones? World J Urol 1993; 11:54-8.

[17] Anderson, K. R., Keetch, D. W., Albala, D. M., Chandhoke, P. S., McClennan, B. L. and Clayman, R. V.: Optimal therapy for the distal ureteral stone: extracorporeal shockwave lithotripsy versus ureteroscopy. J. Urol., 152: 62,1994

[18]Chang, S., Ho, C. and Kuo, H.: Ureteroscopic treatment of lower ureteral calculi in the era of extracorporeal shock wave lithotripsy: from a developing country point of view. J. Urol., 150:1395, 1993.

[19]Kohrmann K U, Rassweiler J J, Manning M, Mohi G, Henkel. 